Eskişehir Osmangazi Üniversitesi ïBF Dergisi

Aralık 2017, C. 12, S. 3, 1- 14

Başvuru : 23.02.2016

Kabul : :03.11.2016

\title{
Nominal Döviz Kuru ve Sektörel Üretim Hacminin Ampirik Analizi: Türkiye Ekonomisi Üzerine Bir İnceleme
}

\author{
Şerife Özşahin ${ }^{1}$ \\ Mustafa Gerçeker² \\ Ahmet $\mathrm{Ay}^{3}$
}

Nominal Döviz Kuru ve Sektörel Üretim Hacminin Ampirik Analizi: Türkiye Ekonomisi Üzerine Bir İnceleme

Öz

Bu çalışma, Türkiye ekonomisinin yedi alt sektöründe nominal döviz kuru ve sektörel üretim hacmi arasındaki ilişkiyi para arzı, kamu harcamaları, petrol fiyatları ve işsizlik oranı gibi kontrol değişkenlerin yardımıyla tespit etmeyi amaçlamaktadır. Bu doğrultuda 1998.Q1-2015.Q3 dönemi için sınır testi ve ARDL yöntemi kullanılarak uzun dönemli muhtemel ilişkiler saptanmaya çalışılmıştır. Yapılan ekonometrik analizler sonucunda inşaat sektörü dışında kalan diğer sektörlerde, sektörel üretim ve nominal döviz kuru arasında uzun dönem ilişki olduğuna yönelik bulgulara ulaşılmış ve bu doğrultuda altı sektör için uzun dönem katsayılar tahmin edilmiştir. Elde edilen bulgular imalat sanayi gibi ithal girdi kullanımının yüksek olduğu sektörlerde nominal döviz kurundaki yükselişlerin maliyet etkisi yaratarak sektörel çıktı hacmini olumsuz yönde etkilediğini ortaya koymaktadır.

Anahtar Kelimeler: Nominal Döviz Kuru, Sektörel Çıktı, Sınır Testi ve ARDL Metodu, Türkiye
The Empirical Analysis of Nominal Exchange Rate and Sectoral Output: An Investigation on Turkish Economy

\begin{abstract}
This study aims to investigate the relationship between nominal exchange rate and sectoral output in seven subsectors of the Turkish economy by using control variables including money supply, public expenditure, oil prices and unemployment rate. Possible relations were tried to be determined by using bound test and ARDL method for the period 1998.Q1-2015Q3. It was concluded that there is a long-run relationship in all sectors excluding construction and accordingly, long-run coefficients and equations were estimated for six sectors. The estimation of long-run coefficients indicates that the rise in the nominal exchange rate affects sectoral output negatively at sectors where imported inputs are high because of the cost effect such as manufacturing industry.
\end{abstract}

Keywords: Nominal Exchange Rate, Sectoral Output, Bound Test and ARDL Method, Turkey

\section{Giriş}

Sabit döviz kuru uygulamasına dayanan Bretton Woods sisteminin 1973 yılında çökmesiyle birlikte içinde gelişmişülkelerin de bulunduğu birçok ülke, sabit kur sistemini terk ederek dalgalı döviz kuru sistemine geçiş yapmıştır. Bu geçiş sürecinin döviz kurlarında yol açtığı ciddi dalgalanmalar yanında ekonomik belirsizlikleri de tetiklemesi, siyasi otoriteleri ve konuyla ilgili araştırmacıları bu dalgalanmaların toplam ticaret ve üretim hacmine etkisini incelemeye yöneltmiştir (Köse vd., 2008: 26).

Bir ülkenin ulusal para biriminin yabancı paralar karşısında değer kaybetmesi veya idari bir kararla değerinin düşürülmesi anlamına gelen devalüasyon uygulamasının söz konusu ülkede ithalatı pahalılaştırarak ihraç ürünlerini ucuzlatacağı ve ülkeye dış ticarette rekabet üstünlüğü sağlayacağı ifade edilmektedir (Krugman ve Taylor, 1978: 445). Ancak bu hususta yapılan pek çok ampirik çalışmanın bulguları, nominal değer kaybının yurt içi üretim hacmi üzerinde yaratacağı etkiye yönelik kesin bir çıkarım yapmanın mümkün olmayacağını; bu etkileşimin pozitif

${ }^{1}$ Yrd. Doç. Dr., Necmettin Erbakan Üniversitesi SBBF, İktisat Bölümü. sozsahin@konya.edu.tr

2 Yrd. Doç. Dr., Selçuk Üniversitesi iiBF, İktisat Bölümü. mgerceker@selcuk.edu.tr

${ }^{3}$ Prof. Dr. Selçuk Üniversitesi iiBF, iktisat Bölümü, ahmetay@selcuk.edu.tr 
veya negatif yönde olabileceğini göstermektedir. Bu bağlamda yurt içi üretim hacmi üzerindeki nihai etkinin, toplam talep ve toplam arz eğrilerinin ulusal paranın değer kaybına karşı göstereceği tepkiye bağlı olacağı savunulmaktadır. Ulusal parada yaşanan değer kaybının net ihracatı artırması sonucu yarattığı talep genişlemesi, kur artışı sonucu ithal girdi maliyetindeki yükselişin yol açtığı arz düşüşünden daha fazla ise bu durumda genişletici etkinin olacağı yorumu yapılabilecektir (Bahmani-Oskoee ve Mirzaie, 2000: 51).

Daha açık bir ifadeyle ulusal paranın değer kaybına uğraması ile ithal ürünlerin yerli mallar karşısında daha pahalı hale gelmesi, tüketicileri yurtiçi mallara yönelterek toplam talebi artıracaktır. Bu doğrultuda yabancı rakipleri karşısında göreceli olarak daha da ucuzlayan yerli mallar, söz konusu ülkede ihracatı artırarak ülkenin cari işlemler dengesinde iyileşmeye yol açacak ve ekonominin genelinde üretim ve istihdam artışı gibi genişletici etkileri beraberinde getirecektir (Krugman vd., 2012: 475-476). Buna karşın, literatürde devalüasyonların daraltıcı olabileceği, bir diğer ifadeyle, reel döviz kurundaki değişmelerin çıktı hacmi üzerinde negatif etkiler yaratabileceğine yönelik açıklamalar da mevcuttur. Bu konuda yapılan çalışmalara göre, nominal devalüasyon neticesinde ithal girdiden ötürü ortaya çıkan maliyet etkisine ek olarak Pigou etkisi olarak da tanımlanan bir etkileşim ortaya çıkacak ve yükselen kurun fiyatlara yansıması reel gelirde düşüş yaratarak tüketim harcamaları ve çıktı hacmini azaltabilecektir. Krugman ve Taylor (1978), devalüasyon neticesinde ortaya çıkan fiyat hareketlerinin reel gelirde düşüşe yol açarak her zaman yurtiçi talebi artırıcı sonuçlar vermeyeceğini dile getirmektedir. Ayrıca nominal ücretlerin katı olduğu kısa dönemde, aramalı ithal maliyetindeki yükseliş de toplam gelirin ücretliler aleyhine yeniden dağılımına da yol açacaktır (Edwards, 1986: 501). Ulusal paranın değer kazanması veya revalüasyon yapılması durumlarında ise yukarıda bahsedilen durumların tam tersi yönünde yorumlamalar yapılabilecektir.

Nominal döviz kurundaki değişmelerin ülke geneli itibariyle toplam üretim ve alt sektörler bazında sektörel çıktı hacmi üzerine etkisini inceleyen bir takım çalışmalar bulunmaktadır. Bu çalışma, Bahmani-Oskoee ve Mirzaie (2000)'nin ABD ekonomisi üzerine yapmış oldukları çalışmanın metodolojisinden yararlanarak Türkiye ekonomisi için nominal döviz kurundaki değişmenin sektörel üretim hacmi üzerinde yarattığı etkiyi, ekonometrik yöntemler yardımıyla incelemeyi amaçlamaktadır.

\section{Literatür Taraması}

Nominal döviz kurunun değer kaybetmesi veya değer kazanmasının toplam çıktı hacmi üzerinde yarattığı etkiyi araştıran pek çok çalışma bulunmasına rağmen döviz kuru değişmelerinin özellikle sektörel düzeyde etkisini irdeleyen çalışmaların sayıca yetersiz kalması gerek yerli gerekse yabancı literatürde karşımıza çıkan ortak bir durumdur. Bu bağlamda döviz kuru değişmelerin toplam çıktı hacmi ve sektörel üretim üzerine etkisini inceleyen sınırlı sayıdaki çalışmaların eriştikleri bulgular aşağıda özetlenmiştir.

Gylfason ve Schmid (1983), ABD'nin de içinde bulunduğu 10 ülke için \%10 düzeyinde bir devalüasyonun reel çıktıda meydana getirdiği etkileri araştırmışlardır. Elde edilen tahmin sonuçları devalüasyonların ABD ekonomisinde reel çıktı hacmini artıran sonuçlar verdiğini göstermiştir. ABD ekonomisi üzerine yapılan bir diğer çalışmada Branson ve Love (1986), reel döviz kurlarındaki hareketliliğinin imalat sanayi çıktı ve istihdam hacmi üzerindeki etkisini araştırmışlardır. Yapılan ekonometrik analiz neticesinde döviz kuru hareketlerinin imalat sanayi çıktı hacmi üzerinde önemli etkileri bulunduğu ve doların değer kaybı neticesinde birçok sektörde üretim hacminin artacağına yönelik bulgular elde edilmiştir. 
Agenor (1991), reel döviz kurlarındaki değişmelerin çıktı hacmi üzerindeki etkisini 19781987 dönemi için 23 ülkenin yıllık verileriyle araştırmıştır. Analizden elde edilen bulgular, reel döviz kurlarında beklenen değer kayıplarının ekonomik aktivite üzerinde negatif bir etki bıraktığını, beklenmeyen değer kayıplarının ise çıktıda pozitif bir etkiye sahip olduğunu ortaya koymaktadır. 1970-1991 yıllarını kapsayan verilerle nominal devalüasyonların Meksika ekonomisinin tarım, balıkçıık ve ormancılık; imalat; madencilik, inşaat; finans ve sigorta; hizmet; taşıma ve iletişim; otel ve restoran; elektrik ve enerji sektörlerinin reel çıktı düzeyi üzerine etkisini inceleyen İşcan (1997), tarım sektörü dışındaki diğer sektörlerde devalüasyonun kısa dönemde daraltıcı etkilerinin bulunduğunu tespit etmiştir.

Bahmani-Oskoee ve Mirzae (2000), ABD ekonomisinin sekiz farklı sektöründe üretim hacmi ve dolar değeri arasındaki uzun dönemli ilişkiyi eş-bütünleşme yöntemi ile incelemişlerdir. Çaış̧mada, "tarım, ormancılık ve balıkçılık; imalat; toptancılık; perakendecilik; finans, sigorta ve emlak; hizmet; madencilik ve inşaat sektörleri ele alınmıştır. Johansen eş-bütünleşme testi bulguları her bir sektörde bir adet ko-entegrasyon vektörünün varlığına işaret etmesine rağmen, pek çok sektörde dışlama etkisinin ortaya çıkması ve sektörel çıktı ile efektif döviz kurları arasındaki bağıntı nedeniyle eş-bütünleşme ilişkisinin varlığı (uzun dönemli ilişki) tespit edilememiştir.

Döviz kuru dalgalanmaları ve ekonomik faaliyet hacmi arasındaki ilişkiyi ABD örneği üzerinden inceleyen Kandil ve Mirzae (2000), döviz kurunda meydana gelen değişmelerin sanayi üretimi üzerinde minimal etki bıraktığını ortaya koymuşlardır. Döviz kuru sapmalarının gelişmekte olan ülkelerin ekonomik büyüme hızlarını ne yönde etkilediğini konu edinen çalışmasında Toulaboe (2000), 33 gelişmekte olan ülkenin kişi başı GSYiH artış oranı ve döviz kurundan sapma verilerini kullanmıştır. Ortaya çıkan sonuçlar reel döviz kurundaki sapmaların ekonomik büyümeyle negatif yönde korelasyonlu olduğunu göstermektedir.

Aguirre ve Calderon (2005), reel döviz kurlarındaki sapma ve oynaklığın ekonomik büyümeye etkisini, 60 ülke için 1965 - 2003 dönemini içeren verilerle panel data yöntemi kullanarak analiz etmişlerdir. Elde edilen bulgulara göre, eksik değerlenmenin yüksek boyutlarda olması büyümeyi olumsuz yönde etkilemesine rağmen, makul kabul edilecek ölçülerdeki eksik değerlenme büyümeyi olumlu yönde etkilemektedir. Diğer bir ifadeyle ekonomik büyüme, reel döviz kurlarındaki yüksek oranda oynaklıktan ve sapmadan olumsuz yönde etkilenmektedir.

Ibrahim (2007), Malezya için reel efektif döviz kurları ile toplam çıktı hacmi ve sekiz alt sektörün çıktı düzeyi arasındaki ilişkiyi Bahmani-Oskoee ve Mirzae (2000) çalışmasına benzer bir yöntemle analiz etmiştir. Çok değişkenli eş-bütünleşme testinin uygulandığı çalışma sonucunda hem toplam çıktı hacmi hem de tüm sektörlerin reel efektif döviz kuru ile uzun dönem ilişkisi olduğu bulgusu elde edilmiştir. Reel döviz kurunun ekonomik büyüme üzerine etkisini Türkiye ekonomisi örneğinde Granger nedensellik testi, varyans ayrıştırma ve etki - tepki analizlerini kullanarak araştıran Çatık (2007), Türkiye'de reel döviz kurunun denge değerinin altında tutulması nedeniyle uzun dönem çıktı hacmini düşürdüğüne yönelik sonuçlara ulaşmıştır.

Ay vd. (2008), Türkiye'de reel döviz kurunun toplam çıtıtı ile nedensellik ilişkisini 1990.Q12006.Q3 dönemine ait üçer aylık verilerle incelemişlerdir. Çalışmada toplam çıktı hacmi için reel GSYiH, döviz kuru için reel efektif döviz kuru değişkenleri kullanılmıştır. Ampirik analiz sonuçları söz konusu dönemde Türkiye'de reel efektif döviz kurunun toplam çıktı hacmini artırdığını göstermiştir. Türkiye' de reel döviz kuru ile ekonomik büyüme arasındaki ilişkiyi iki farklı model oluşturarak inceleyen Uğurlu (2009), eriştiği nedensellik analizi sonuçlarına dayanarak reel döviz kurunun GSYiH'nın Granger nedeni olduğunu belirtmektedir. Etki - Tepki ve Varyans Ayrıştırma 
analiz sonuçları ise reel döviz kurundaki artışların GSYiH üzerinde kısa dönemde artırıcı etkisi olmakla birlikte bu etkinin uzun dönemde azaltıcı yönde olduğunu ortaya koymuştur.

Sarı (2009), Türkiye örneğinde 1986.10-2006.01 dönemine ait aylık verilerle döviz kuru oynaklığı, faiz oranı ve para arzındaki artışların toplam çıktı(GSMH) hacmi üzerinde yol açtığı etkileri incelemiştir. Çalışmadan elde edilen bulgular, Türkiye'de imalat sanayi sektörünün faiz oynaklığından ziyade döviz kurundaki oynaklıktan etkilendiğini göstermektedir. Buna göre döviz kurundaki belirsizlik, sektörel üretim miktarını, ihracat ve ithalat kanalıyla olumsuz yönde etkilemektedir. döviz kurundaki sapmaların tarım, imalat ve madencilik sektörü üzerindeki etkisini Zimbabwe örneği üzerinde inceleyen Masunda (2011), yaptığı ekonometrik analiz sonucunda reel döviz kurunda yaşanan dengesizliklerin söz konusu sektörlerde üretim hacmini olumsuz etkilediği sonucuna ulaşmıştır.

\section{Veri Seti ve Ekonometrik Model}

Bu çalışmada sektörel çıktı düzeyi ve nominal efektif döviz kuru ilişkisi, Bahmani-Oskooee ve Mirzaie(2000) çalışmasında kullanılan ve Eşitlik 1'de ifade edilen model yardımıyla belirlenmeye çalışılmıştır.

$$
Q_{i t}=F\left[U N_{t}, O I L P_{t}, G_{t}, M_{t}, E X_{t}\right]
$$

Eşitlik 1'de yer alan $Q_{i t}$ her bir sektöre ait çıktı düzeyini, $U N_{t}$ işsizlik oranını, $O I L P_{t}$ petrol fiyatlarını, $G_{t}$ kamu harcamalarını, $M_{t}$ reel para arzı büyüklüğünü ve $E X_{t}$ ise nominal efektif dolar döviz kurunu temsil etmektedir. Her bir sektöre ait çıktı düzeyinin bağımlı değişken olduğu yedi farklı model üzerinden ekonometrik analizler yapılmıştır. Bu amaçla kullanılacak sektörel tanımlamalar aşağıda ifade edilmiştir.

$Q_{1}$ : Tarım, ormancılık ve balıkçılık sektörlerine ait toplam çıktı hacmi

$Q_{2}$ : İmalat sektörüne ait toplam çıktı hacmi

$Q_{3}$ : Toptancılık sektöründeki toplam çıktı hacmi

$Q_{4}$ : Inş̧aat sektöründen elde edilen toplam çıktı

$Q_{5}$ : Finans ve sigorta faaliyetlerinden elde edilen toplam çıktı

$Q_{6}$ : Hizmet sektörüne ait toplam çıktı hacmi

$\mathrm{Q}_{7}$ : Madencilik sektörüne ilişkin toplam çıktı düzeyi

Bahmani-Oskooee ve Mirzaie(2000)'e göre iş çevrimini temsil etmesi amacıyla modele dahil edilen $U N_{t}$ değişkeninin, işsizlik oranındaki artışın toplam talepte ve her bir sektörün üretim düzeyinde azalışa neden olması dolayısıyla negatif işaretli çıkması beklenmektedir. Ayrıca petrol fiyatlarındaki artış da her bir sektörde üretim maliyetini artıracağı için sektörel çıktı düzeyini olumsuz yönde etkileyecektir. Dolayısıyla $O I L P_{t}$ değişkeninin de negatif işaret alması beklenmektedir. Uygulanan maliye ve para politikalarının toplam talep üzerinde genişleyici etki yaratması halinde $G_{t}$ ve $M_{t}$ değişkenlerinin katsayıları pozitif işaretli, aksi halde negatif işaretli olacaktır. Döviz kurlarındaki yükselişin sektörel çıktı hacminde genişleyici etki yaratması halinde nominal efektif döviz kurunu temsil eden $E X_{t}$ değişkeni negatif işaretli bir katsayı alacak, bu işaretin pozitif olması durumunda ise döviz kurundaki değişmelerin daraltıcı etkilerinin daha baskın olduğu söylenebilecektir. 
Çalışmada, 1998.Q1-2015.Q3 dönemine ait üçer aylık veriler logaritmik dönüşümleri yapılarak modellemelerde kullanılmış ve ekonometrik analiz için Eviews 7 paket programından yararlanılmıştır. Her bir sektörün çıktı düzeyi, nominal efektif döviz kuru ve M2 reel para arzı T.C. Merkez Bankası'nın resmi internet sayfasında yer alan Elektronik Veri Dağıtımı Sistemi'nden; kamu harcamaları ve işsizlik oranları Türkiye İstatistik Kurumu veri tabanından, petrol fiyatları ise ABD Resmi Enerji İstatistik Bürosu'ndan alınmıştır.

\section{Metodoloji}

Granger ve Newbold(1974), zaman serisi yöntemleri kullanılarak yapılan ekonometrik analizlerde yer alacak değişkenlerin durağanlık koşulunu sağlaması gerektiğine aksi takdirde tahmin edilen modellerin sahte regresyonlar olacağına önemle vurgu yapmışlardır. Bu açıdan zaman serisi analizlerinde yer alacak değişkenlerin birim kök testine tabi tutulması ve durağanlık koşulunu sağlayıp sağlamadıklarının tesbiti büyük önem taşımaktadır. Bu doğrultuda en yaygın kullanılan yöntemler ADF ve PP birim kök testleridir.

\subsection{Birim Kök Testleri}

Zaman serilerinin sabitli, sabitli-trendli ve sabitsiz formlarına göre üç regresyon üzerinden modellenen ADF birim kök testi Dickey ve Fuller(1981) tarafından geliştirilmiştir. Bu yönteme göre birim kök analizi yapılırken tahmin edilecek modeller Eşitlik 2, 3 ve 4'te ifade edilmiştir.

$$
\begin{array}{ll}
\Delta y_{t}=\delta y_{t-1}+\sum_{i=1}^{m} \alpha_{i} y_{t-1}+u_{t} & \mathbf{2} \\
\Delta y_{t}=\beta_{1}+\delta y_{t-1}+\sum_{i=1}^{m} \alpha_{i} y_{t-1}+u_{t} & \mathbf{4} \\
\Delta y_{t}=\beta_{1}+\beta_{2} t+\delta y_{t-1}+\sum_{i=1}^{m} \alpha_{i} y_{t-1}+u_{t} &
\end{array}
$$

Eşitlik 2, 3 ve 4'te hata terimi $u_{t}$, bağımlı değişkenin bir dönem gecikmeli değeri ise $y_{t-1}$ ile gösterilmektedir. Bu yönteme göre bir seride birim kökün var olması eşitliklerde yer alan $\delta$ teriminin sıfıra eşitliği ile belirlenmektedir. ADF testinde elde edilen istatistiki değer, MacKinnon'un kritik tablo değerleri ile karşılaştırılmakta ve nihai sonuca ulaşılmaktadır (Gujarati, 2004: 817). Karar aşamasında serilerin birim kök içermemesi bir diğer ifadeyle alternatif hipotezin kabul edilmesi için MacKinnon kritik tablo değerinin hesaplanan istatistikten daha büyük olması gerekmektedir.

Phillips ve Perron(1988)'un geliştirdiği Phillips ve Perron birim kök testinde ise regresyona ait hata terimlerinde ortaya çıkacak birim kök ve değişen varyans sorunu doğrudan düzeltilmektedir. Bu yönteme ilişkin hesaplama Eşitlik 5'te yer alan denklem üzerinden yapılmaktadır (Zivot ve Wang, 2006: 127).

$$
\Delta y_{t}=\beta^{\prime} D_{t}+\pi y_{t-1}+u_{t}
$$

Phillips ve Perron(1988) birim kök testinde değişen varyans sorunu $t_{\pi}=0$ ve $T \hat{\pi}$ istatistiklerinin düzeltilmesi ile giderilirken hata teriminde $\left(u_{t}\right)$ birim kökün varlığı da ortadan kaldırılmaktadır. Serilerde birim kökün varlığına ADF testine benzer şekilde hesaplanan istatistik ile kritik değerin mukayesesi ile karar verilmektedir. Kritik tablo değerinin hesaplanan istatistikten daha büyük olması, Phillips-Perron testine göre serinin durağan olduğunun bir göstergesidir. 


\subsection{Sınır Testi ve ARDL Yöntemi}

Ekonometrik çalışmalarda seriler arası uzun dönem ko-entegrasyon ilişkisinin varlığı araştırılırken Engle ve Granger(1987) ve Johansen ve Juselius(1990) tarafından geliştirilen yöntemlerden sıklıkla faydalanılmaktadır. Bu yöntemler uygulamalı çalışmalarda yoğun olarak tercih edilmesine rağmen regresyon denkleminde yer alacak değişkenlerin aynı seviyede durağanlığını şart koşmaktadır. Farklı seviyede durağanlığa sahip seriler arasında uzun dönem ilişkisinin tespiti için ise sınır testi ve ARDL metodundan yararlanılmaktadır.

Pesaran vd.(2001) tarafından geliştirilen sınır testi, modelde yer alacak değişkenler arasında uzun dönemli ilişkinin olup olmadığını tayin etmektedir. Sınır testinin değişkenler arasında uzun dönem ilişkisi olduğuna yönelik sonuç vermesi durumunda Pesaran ve Shin(1999)'in ARDL yöntemi kullanılarak kısa dönem katsayıları elde edilmektedir. Bu çalışmada döviz kurundaki değişmelerin sektörel çıktı üzerine etkisini araştırmak amacıyla Bahmani-Oskooee ve Mirzaie(2000) çalışmasındaki metodoloji takip edilmiştir. Bu doğrultuda tahmin edilecek regresyon denklemi Eşitlik 6'da gösterilmiştir.

$Q_{t}=\beta_{0}+\beta_{1} U N_{t}+\beta_{2} O I L P_{t}+\beta_{3} G_{t}+\beta_{4} M_{t}+\beta_{5} E X_{t}+\varepsilon_{t}$

Sınır testinde bağımlı değişken ve modelde yer alan diğer bağımsız değişkenlere göre düzenlenen sınırlandırılmamış bir hata düzeltme modeli tahmin edilmektedir. Bu çalışmanın bağımlı değişkeni olan sektörel çıktı düzeylerine göre tahmin edilecek sınırlandırılmamış koşullu hata düzeltme modeli Eşitlik 7'de ifade edilmiştir.

$$
\begin{aligned}
\Delta Q_{t}= & c_{0}+c_{1} t+\delta_{1} Q_{t-1}+\delta_{2} U N_{t-1}+\delta_{3} O I L P_{t-1}+\delta_{4} G_{t-1}+\delta_{5} M_{t-1} \\
& +\delta_{6} E X_{t-1}+\sum_{i=1}^{p} \lambda_{i} \Delta Q_{t-i}+\sum_{i=0}^{p} \omega_{i} \Delta U N_{t-i}+\sum_{i=0}^{p} \varphi_{i} \Delta O I L P_{t-i} \\
& +\sum_{i=0}^{p} \gamma_{i} \Delta G_{t-i}+\sum_{i=0}^{p} \theta_{i} \Delta M_{t-i}+\sum_{i=0}^{p} \eta_{i} \Delta E X_{t-i}+u_{t}
\end{aligned}
$$

Eşitlik 7'de cosabit terim; $\Delta$ ise değişkenlerin birinci farklarının kullanıldığını gösteren bir işlemcidir. Her bir değişkene ait uzun dönem katsayılar ise $\delta_{1}, \delta_{2}, \delta_{3}, \delta_{4}$, $\delta_{5}$ ve $\delta_{6}$ ile göstermektedir. Sınır testinin uygulanmasında ilk olarak Eşitlik 7'de ifade edilen denklem, Akaike(AIC) ve Schwarz(SBC) kriterlerinin önerdiği $p$ uygun gecikme uzunlukları ile tahmin edilmektedir. Sınır testinin uygulanmasında önem arzeden bir diğer husus ise uygun gecikme uzunluğu kullanılarak tahmin edilen regresyonların otokorelasyon problemi taşımaması gereğidir (Pesaran ve Shin, 1999: 373, 386).

Modelde yer alan değişkenlerin uzun dönemde ilişkili olduğuna yönelik bir çıkarım ancak regresyonlara ait F istatistiklerinin Pesaran vd.(2001)'ın kritik tablo değerleri ile mukayesesi sonucunda yapılabilecektir. Pesaran vd.(2001)'a ait kritik F tablo değerleri, alt ve üst olmak üzere iki farklı istatistik sunmaktadır. Değişkenler arasında uzun dönemli bir ilişkinin olduğuna karar verilebilmesi için regresyondan elde edilen F istatistiğinin, Pesaran vd.(2001)'ın kritik üst sınır değerinden daha büyük olması gerekmektedir (Pesaran vd., 2001: 290).

Sınır testi sonuçlarının değişkenler arasında uzun dönemli etkileşim olduğunu göstermesi, bir sonraki aşamada ARDL metodu kullanılarak kısa ve uzun dönem katsayılarının hesaplanmasına imkan tanımaktadır. Bir önceki aşamada tayin edilen uygun gecikme uzunluğu ile düzenlenmiş uzun dönem koşullu ARDL modeli Eşitlik 8'de ifade edilmiştir. 


$$
\begin{aligned}
Q_{t}= & c_{0}+\sum_{i=1}^{p_{1}} \alpha_{i} Q_{t-i}+\sum_{i=0}^{q_{1}} \theta_{1 i} U N_{t-i}+\sum_{i=0}^{q_{2}} \theta_{2 i} \text { OILP } P_{t-i}+\sum_{i=0}^{q_{3}} \theta_{3 i} G_{t-i} \\
& +\sum_{i=0}^{q_{4}} \theta_{4 i} M_{t-i}+\sum_{i=0}^{q_{5}} \theta_{5 i} E X_{t-i}+u_{t}
\end{aligned}
$$

Kısa dönem katsayıları veren hata düzeltme modeli Eşitlik 9'da gösterilmiştir.

$$
\begin{aligned}
\Delta Q_{t} & =\mu+\sum_{i=1}^{p} \lambda_{i} \Delta Q_{t-i}+\sum_{i=0}^{p} \omega_{i} \Delta U N_{t-i}+\sum_{i=0}^{p} \varphi_{i} \Delta O I L P_{t-i} \\
& +\sum_{i=0}^{p} \gamma_{i} \Delta G_{t-i}+\sum_{i=0}^{p} \theta_{i} M_{t-i}+\sum_{i=0}^{p} \eta_{i} E X_{t-i}+\vartheta E C M_{t-1}+u_{t}
\end{aligned}
$$

Eşitlik 9'da her bir değişkenin başında yer alan $\gamma_{i}, \theta_{i}, \omega_{i}, \varphi_{i}, \eta_{i}$ ve $\lambda_{i}$, değişkenlere ait kısa dönem katsayılarını, $\vartheta$ ise modelin hata düzeltme terimini temsil etmektedir. Hata düzeltme mekanizmasının iyi işleyebilmesi, $\vartheta$ teriminin negatif işaretli ve istatistiki açıdan anlamlı olması ile ölçülmektedir. Ayrıca modellerde ardışık bağımlılığın kontrolü için Breusch-Godfrey testi, değişen varyansın kontrolü için White testi ve normalite koşulunun sağlanıp sağlanmadığını görmek için ise Jarque-Bera testi uygulanmalıdır.

\section{Analiz Sonuçları}

Sınır testi ve ARDL yöntemi, bağımlı değişkenin birinci farkında durağan olması koşuluyla farklı düzeyde durağanlığa sahip serilerde uzun dönemli ilişkinin varlığını araştırmaya imkan tanımaktadır. . Bu çalışmada serilerin durağanlık düzeylerinin tespit edilmesi amacıyla Dickey ve Fuller(1981)'in ADF testi ile Phillips ve Perron(1988)'un Phillips-Perron(PP) birim kök testleri kullanılmıştır. Tablo 1'de logaritmik dönüşümü yapılan orijinal serilere ait ADF ve PP durağanlık test sonuçları rapor edilmiştir.

Tablo 1: Orijinal Serilere Ait ADF ve PP Durağanlık Testi Sonuçları

\begin{tabular}{lcccc}
\hline & \multicolumn{2}{c}{ ADF } & \multicolumn{2}{c}{ Phillips-Perron } \\
\hline Değişken & Sabitli & Sabitli ve trendli & Sabitli & Sabitli ve trendli \\
\hline Q1 & $0.835(0.99)$ & $-1.767(0.70)$ & $-7.968(0.00)$ & $-12.63(0.00)$ \\
Q2 & $-0.514(0.88)$ & $-3.087(0.11)$ & $-0.907(0.78)$ & $-4.513(0.00)$ \\
Q3 & $-0.629(0.85)$ & $-3.191(0.09)$ & $-0.729(0.83)$ & $-3.518(0.04)$ \\
Q4 & $-0.533(0.87)$ & $-2.351(0.40)$ & $-0.655(0.85)$ & $-2.902(0.16)$ \\
Q5 & $-0.450(0.98)$ & $-2.402(0.37)$ & $-0.555(0.87)$ & $-6.173(0.00)$ \\
Q6 & $-0.819(0.80)$ & $-2.913(0.16)$ & $-0.604(0.86)$ & $-0.585(0.00)$ \\
Q7 & $-0.455(0.89)$ & $-2.401(0.37)$ & $-5.869(0.00)$ & $-7.745(0.00)$ \\
UN & $-2.195(0.20)$ & $-2.419(0.36)$ & $-2.878(0.05)$ & $-2.547(0.04)$ \\
OILP & $-1.866(0.34)$ & $-1.863(0.66)$ & $-1.876(0.34)$ & $-1.196(0.90)$ \\
G & $-0.914(0.77)$ & $-3.109(0.11)$ & $1.166(0.68)$ & $-2.866(0.17)$ \\
M & $-4.783(0.00)$ & $-2.557(0.30)$ & $4.600(0.00)$ & $-2.548(0.30)$ \\
EX & $-2.911(0.04)$ & $-2.887(0.17)$ & $3.566(0.00)$ & $-3.049(0.12)$ \\
\hline \multicolumn{5}{c}{ Kritik Değerler } \\
\hline \%1 & -3.542 & -4.115 & -3.527 & -4.094 \\
\%5 & -2.910 & -3.485 & -2.903 & -3.475 \\
\%10 & -2.592 & -3.170 & -2.589 & -3.165 \\
\hline
\end{tabular}

Not: Parantez içinde yer alan rakamlar birim kök testlerine ait olasılık değerleridir. 
Tablo 1'de yer alan birim kök test sonuçları incelendiğinde serilere ait durağanlık düzeylerinin birim kök yöntemlerine göre farklılaştığı görülmektedir. Ancak genel bir yorumlama ile tüm serilerin birim kök yöntemlerinden en az birine göre seviyede birim kök içerdiği ifade edilebilecektir. Serilerin birinci farklarına uygulanan ADF ve PP testleri neticesinde ulaşılan bulgular Tablo 2' de gösterilmiştir.

Tablo 2: Birinci Farkları Alınan Serilere Ait ADF ve PP Birim Kök Testi Sonuçları

\begin{tabular}{lcccc}
\hline & \multicolumn{2}{c}{ ADF } & \multicolumn{2}{c}{ Phillips-Perron } \\
\hline Değişken & Sabitli & Sabitli ve trendli & Sabitli & Sabitli ve trendli \\
\hline Q1 & $-3.622(0.00)$ & $-3.868(0.00)$ & $-14.25(0.00)$ & $-14.13(0.00)$ \\
Q2 & $-3.980(0.00)$ & $-3.929(0.01)$ & $-26.48(0.00)$ & $-28.44(0.00)$ \\
Q3 & $-4.245(0.00)$ & $-4.203(0.00)$ & $-18.03(0.00)$ & $-18.88(0.00)$ \\
Q4 & $-3.311(0.01)$ & $-3.283(0.07)$ & $-10.50(0.00)$ & $-10.75(0.00)$ \\
Q5 & $-3.003(0.04)$ & $-3.083(0.11)$ & $-13.67(0.00)$ & $-13.64(0.00)$ \\
Q6 & $-3.314(0.01)$ & $-3.309(0.07)$ & $-17.61(0.00)$ & $-17.85(0.00)$ \\
Q7 & $-12.96(0.00)$ & $-13.02(0.00)$ & $-13.82(0.00)$ & $-13.93(0.00)$ \\
UN & $-3.285(0.02)$ & $-3.627(0.03)$ & $-16.56(0.00)$ & $-24.52(0.00)$ \\
OILP & $-5.824(0.00)$ & $-6.952(0.00)$ & $-5.990(0.00)$ & $-6.632(0.00)$ \\
G & $-11.80(0.00)$ & $-11.74(0.00)$ & $-13.24(0.00)$ & $-13.35(0.00)$ \\
M & $-6.956(0.00)$ & $-8.087(0.00)$ & $-6.976(0.00)$ & $-8.091(0.00)$ \\
EX & $-5.587(0.00)$ & $-5.575(0.00)$ & $-5.574(0.00)$ & $-5.793(0.00)$ \\
\hline \multicolumn{5}{c}{ Kritik Değerler } \\
\hline \%1 & -3.534 & -4.105 & -3.528 & -4.096 \\
$\% 5$ & -2.906 & -3.480 & -2.904 & -3.476 \\
$\% 10$ & -2.591 & -3.168 & -2.589 & -3.165 \\
\hline
\end{tabular}

Not: Parantez içinde yer alan rakamlar birim kök testlerine ait olasılık değerleridir.

Tablo 2'de yer verilen sonuçlar incelendiğinde seviye değerinde durağan olmayan serilerin birinci farklarında durağanlaştığı görülmektedir. Ekonometrik analizlerde kullanılacak tüm serilerin en fazla birinci düzeyde durağan çıktığı, teknik bir ifadeyle I(1) olduğu anlaşıldığı için seriler arası uzun dönemli ilişkinin varlığına yönelik sınamalar yapılabilecektir.

Değişkenler arasında uzun dönem ilişkisinin varlığını araştırmak için kullanılan sınır testi, Eşitlik 7 'de ifade edilen denklemin sıradan en küçük kareler yöntemiyle tahminini gerektirir. Eşitlik 7'de yer alan $p$ uygun gecikme uzunluğunun tesbiti için Akaike ve Schwarz kriterlerinin önerisi dikkate alınmaktadır. Ayrıca önerilen gecikme uzunluğu kullanılarak tahmin edilen regresyonlarda otokorelasyon sorununun varlığı Breusch-Pagan Lagrange çarpanı(LM) ile kontrol edilmiş ve ulaşılan sonuçlar Tablo 3'de özetlenmiştir.

Tablo 3: Uygun Gecikme Uzunluğunun Belirlenmesi

\begin{tabular}{lcccccccc}
\hline Modeller & \multicolumn{4}{c}{ Deterministik trendli } & \multicolumn{4}{c}{ Deterministik trendsiz } \\
\cline { 2 - 8 } Model 1 & $\mathrm{p}$ & $\mathrm{AIC}$ & $\mathrm{SCH}$ & $\mathrm{LM}(1)$ & $\mathrm{p}$ & $\mathrm{AIC}$ & $\mathrm{SCH}$ & $\mathrm{LM}(1)$ \\
\cline { 2 - 8 } Model 2 & 3 & 1.76 & 2.18 & $3.373(0.06)$ & 2 & 1.75 & 2.14 & $6.739(0.00)$ \\
Model 3 & 1 & -3.14 & -2.72 & $0.556(0.45)$ & 1 & -2.88 & -2.49 & $8.485(0.00)$ \\
Model 4 & 1 & -2.94 & -2.51 & $0.821(0.36)$ & 1 & -2.79 & -2.40 & $3.099(0.07)$ \\
Model 5 & 1 & -2.51 & -2.09 & $0.040(0.83)$ & 1 & -2.52 & -2.13 & $0.258(0.61)$ \\
Model 6 & 3 & -1.86 & -1.44 & $4.070(0.06)$ & 3 & -1.80 & -1.41 & $6.769(0.00)$ \\
Model 7 & 3 & -3.81 & -3.39 & $2.226(0.13)$ & 1 & -3.46 & -3.07 & $0.118(0.73)$ \\
\hline
\end{tabular}

Not: $p$ değeri önerilen uygun gecikme uzunluğunu; parantez içindeki rakamlar ise olasılık değerlerini ifade etmektedir. 
Tablo 3'te yer alan sonuçlar değerlendirildiğinde, Akaike ve Schwarz bilgi kriterlerinin iki model haricinde aynı gecikme uzunluklarını verdiği görülmektedir. Bu gecikme uzunluklarına göre tahmin edilen modeller, Breusch-Pagan Lagrange çarpanına göre otokorelasyon sorunu taşımamaktadır.

Tablo 4'te ise trendli ve trendsiz modellerin sınır testi sonuçları sunulmaktadır. Sınır testinde seriler arası eş-bütünleşme ilişkisinin varlığını tayin etmek amacıyla Pesaran vd.(2001) tarafından verilen kritik değerlere ve hesaplanan $\mathrm{F}$ istatistiklerine ihtiyaç duyulmaktadır. Hesaplanan F istatistiklerinin Pesaran vd.(2001) tarafından verilen üst kritik değerden büyük olması durumunda seriler arası uzun dönemli ilişkinin olduğuna dair bir çıkarım yapılabilecek ve boş hipotez reddedilecektir.

Tablo 4: Sınır Testi F istatistikleri ve Pesaran vd.(2001) Kritik Değerleri

\begin{tabular}{|c|c|c|c|c|}
\hline \multirow[t]{2}{*}{ Bağımlı değişken } & \multicolumn{2}{|c|}{ Trendli model } & \multirow{2}{*}{$\frac{\text { Trendsiz model }}{\text { F-iii }}$} & \multirow[t]{2}{*}{ Sonuç } \\
\hline & F-iv & $F-v$ & & \\
\hline Tarım & 703.9 & 816.1 & 2.078 & Eşbütünleşme var. \\
\hline İmalat & 6.365 & 7.213 & 3.325 & Eşbütünleşme var. \\
\hline Toptancılık & 3.539 & 4.054 & 2.038 & Eşbütünleşme var. \\
\hline İnşaat & 2.049 & 2.323 & 2.123 & Eşbütünleşme yok. \\
\hline Finans & 5.692 & 6.379 & 4.416 & Eşbütünleşme var. \\
\hline Hizmet & 7.805 & 9.075 & 2.628 & Eşbütünleşme var. \\
\hline Madencilik & 4.081 & 4.025 & 4.813 & Eşbütünleşme var. \\
\hline \multicolumn{3}{|c|}{$\begin{array}{l}\text { Pesaran vd.(2001) alt ve üst sınır kritik de- } \\
\text { gerleri }\end{array}$} & \multicolumn{2}{|c|}{$\begin{array}{c}\text { Pesaran vd.(2001) alt ve üst sınır kritik de } \\
\text { ğerleri }\end{array}$} \\
\hline$\% 1$ & 3.60 & 4.90 & 3.15 & 4.43 \\
\hline$\% 5$ & 2.87 & 4.00 & 2.45 & 3.61 \\
\hline$\% 10$ & 2.53 & 2,59 & 2.12 & 3.23 \\
\hline
\end{tabular}

Not: Kritik değerler Pesaran vd.(2001) çalışmasından elde edilmiştir.

Tablo 4'te sunulan sonuçlar Pesaran vd.(2001)'ın kritik alt ve üst kritik değerleriyle kıyaslandığında inşaat sektörü çıktı düzeyinin bağımlı değişken olduğu model haricindeki diğer modellerde, hesaplanan değerlerin kritik üst değerden daha büyük olduğu görülmektedir. Dolayısıyla inşaat sektörüne ait çıktı düzeyinin bağımlı değişken olduğu Model 4 haricindeki diğer modellerde uzun dönemli ilişki olduğuna yönelik bir çıkarım yapılabilecek ve serilerin kısa ve uzun dönem katsayılarının elde edileceği ARDL modeline geçiş yapılabilecektir.

İnşaat sektöründe uzun dönemli ilişkinin olduğuna dair bir bulguya ulaşılamamasının nedeni ise girdi-çıktı tablolarının incelenmesiyle anlaşılabilecektir. TÜik tarafından yayınlanan 2002 yılındaki son girdi-çıktı tablosu incelendiğinde, inşaat sektörünün yüksek düzeyde yurtiçi ara girdi kullanan bir sektör olduğu ve ithal girdi miktarının çok düşük seviyede kaldığı görülmektedir (TÜik, 2002). Dolayısıyla ithal girdi kullanımının çok düşük seviyede kalması, inşaat sektörü için sektörel çıktı düzeyi ile döviz kurlarındaki değişim arasında uzun dönemli bir ilişki ortaya çıkmamasının nedeni olarak belirtilebilecektir.

ARDL yönteminde gecikme uzunluğu olarak Akaike kriterinin önerisi dikkate alınmıştır. Aralarından uzun dönem ilişkinin olmadığına yönelik bulgulara ulaşılan inşaat sektörünün bağımlı değişken olduğu modele yönelik herhangi bir tahmin yapılmamıştır. Diğer sektörler için değişkenlerin uzun dönem katsayılarını elde etmek amacıyla tahmin edilecek ARDL denklemi bulguları Tablo 5'te sunulmuştur. 
Tablo 5: ARDL Modeli Sonuçları ve Uzun Dönem Katsayıları

\begin{tabular}{|c|c|c|c|c|c|c|c|}
\hline & & UN & OILP & G & M & EX & C \\
\hline \multirow{6}{*}{ 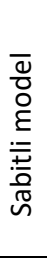 } & Tarım & 0.058 & 0.031 & $0.256^{* *}$ & 0.006 & 0.032 & $10.63 * * *$ \\
\hline & İmalat & $-0.31 * *$ & $-0.17 * * *$ & 0.082 & $0.27^{* * *}$ & $0.17 * *$ & $10.5^{* * *}$ \\
\hline & Toptan & -0.140 & 0.007 & 0.096 & $0.160^{*}$ & -0.023 & $10.7 * * *$ \\
\hline & Finans & $-0.30 * * *$ & -0.25 & $0.25 * * *$ & $0.41 * * *$ & -0.166 & $4.89 * * *$ \\
\hline & Hizmet & -0.069 & 0.038 & $0.141^{*}$ & $0.106 * *$ & -0.022 & $11.9 * * *$ \\
\hline & Madencilik & $-0.17^{* *}$ & 0.013 & 0.055 & $0.11^{* * *}$ & $0.19 * * *$ & $9.38 * * *$ \\
\hline \multirow{6}{*}{ 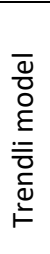 } & Tarım & 0.001 & $-0.04 * *$ & 0.003 & $0.09 * * *$ & 0.031 & $15.7^{* * *}$ \\
\hline & İmalat & $-0.28 * * *$ & $-0.026 * *$ & $0.32 * * *$ & 0.053 & $0.17^{* * *}$ & $18.9 * * *$ \\
\hline & Toptan & $-0.18^{*}$ & $0.11^{* *}$ & $0.44 * * *$ & -0.042 & $0.26^{* *}$ & $21.1 * * *$ \\
\hline & Finans & $-0.11^{* *}$ & $-0.10 * *$ & $0.16 * * *$ & $0.21^{* * *}$ & -0.015 & $8.58 * * *$ \\
\hline & Hizmet & $-0.16 * * *$ & -0.032 & $0.16 * * *$ & $0.08^{* * *}$ & -0.002 & $16.6^{* * *}$ \\
\hline & Madencilik & $-0.12^{* *}$ & 0.005 & 0.078 & $0.13^{* * *}$ & $0.18 * * *$ & $8.79 * * *$ \\
\hline
\end{tabular}

Not: $* * *, * *$ ve $*$ sırasıyla \%1, \% 5 ve \% 10 önem düzeyinde anlamlılığı göstermektedir.

Tablo 5'te verilen uzun dönem katsayıları incelendiğinde tarım sektörü dışındaki sektörlerde işsizlik oranlarının ilgili sektörlere yönelik çıktı seviyesini düşürdüğü görülmektedir. Tarım ve toptancılık sektörünün bağımlı değişken olduğu sabitli modeller dışındaki diğer tüm modellerde, işsizlik oranı sektörel çıktıyı negatif yönde etkileyen istatistiksel açıdan anlamlı bir değişkendir. Trendli model incelendiğinde ise tarım sektörü dışında kalan diğer tüm sektörlerde işsizlik oranındaki artış sektörel üretimi azaltan anlamlı bir değişken olarak göze çarpmaktadır. Ayrıca petrol fiyatlarındaki yükseliş de petrolün girdi olarak kullanıldığı imalat sanayinin sabitli ve trendli modellerinde sektörel çıktı üzerinde negatif etki yaratan anlamlı bir değişkendir.

Regresyon sonuçlarından ulaşılan uzun dönem katsayılarına bakılarak, kamu harcamalarındaki artışın tüm sabitli ve trendli modellerde sektörel çıktı üzerinde genişletici sonuçları olduğu yorumu yapılabilecektir. Kamu harcamalarındaki artış sabitli modellerde tarım, finans ve hizmet sektörü çıktı düzeyini; trendli modellerde ise imalat, toptan, finans ve hizmet sektörlerinin toplam üretim hacmini etkileyen istatistiksel olarak anlamlı bir değişkendir. Bu katsayılar para politikası açısından değerlendirildiğinde ise uygulanan para politikasının sabitli modelde tarım sektörü haricinde, trendli modelde ise imalat ve toptancılık sektörü haricinde sektörel çıktıyı olumlu yönde etkileyen anlamlı bir değişken olduğu yorumu yapılabilecektir. Para arzının negatif işarete sahip olduğu ve genişletici para politikasının sektörel üretimi olumsuz yönde etkilediği sonucu elde edilen toptancılık sektöründe para arzı istatistiksel açıdan anlamlı değildir.

Döviz kurundaki değişmelerin sektörel çıktı üzerindeki etkisi incelendiğinde ise sabitli modelde imalat sanayi ve madencilik sektörlerini, trendli modelde ise imalat, toptancılık ve madencilik sektörlerini pozitif yönde etkileyen anlamlı bir değişken olduğu görülmüştür. Bu etkileşim sabitli modellerde imalat sanayi için \%5 ve madencilik sektörü için \%1 iken trendli modellerde imalat ve madencilik sektörü için \%1, toptancılık sektörü için \%5 düzeyinde anlamlılığa sahiptir. İsmi geçen bu sektörler dışındaki diğer sektörlerde döviz kurundaki yükselişin çıktı hacmine etkisi genişletici olsa bile bu etki, istatistiksel açıdan anlamlı değildir. 
Nominal efektif döviz kuru ve sektörel çıktı arasındaki daraltıcı etkileşim, sektörlerin ithal girdi kullanım düzeylerine bakılarak açıklanabilecektir. Tüik tarafından yayınlanan girdi-çıktı tablosu incelendiğinde, sektörel çıktı hacmi üzerindeki bu daraltıcı etkilerin, ilgili tüm sektörlerin ithal girdi kullanımı ve ithalat kanalı aracılığıyla ortaya çıktığını gözlenebilecektir. Yükselen döviz kurlarının ithal girdiler için daha fazla ödemeyi gerektirmesinden ötürü oluşan maliyet baskısı, sektörel çıktı düzeyi üzerinde azaltıcı etki yaratmaktadır.

Ayrıca imalat sanayi kapsamında yer alan birçok alt sektörde verimlilik artışının sağlanabilmesi büyük ölçüde değişen teknolojinin takibini ve yeni teknolojilere uyumu gerekli kılmaktadır. Dolayısıla bu sektörlerde faaliyette bulunan firmalar için yenilenmenin bir zorunluluk olması da ithalatı sürekli hale getirmektedir (Küçükkiremitçi, 2011). Ayrıca analiz sonuçlarına göre yerli paranın değer kaybı sonucu daha pahalı hale gelen ithalat, imalat sanayi çıktı düzeyi ile reel kur arasındaki daraltıcı etkileşimi açıklamaktadır.

Tarım sektörü açısından sonuçlar değerlendirildiğinde ise tarım sektöründe ara girdi miktarının düşük olması ve tarımsal çıktı miktarının yoğun olarak hava koşullarına bağımlı olması nedeniyle, tarımsal çıktı düzeyi ile döviz kuru arasında istatistiksel olarak anlamlı bir ilişkinin ortaya çıkmadığı belirtilebilir. Analiz sonuçlarında da bu durum, nominal kur düzeyinin tarım sektörü çıktı hacmini etkileyen anlamlı bir değişken olmaması ile izah edilebilecektir.

Modellerde yer alan değişkenlerin kısa dönem etkileşimini görmek amacıyla ARDL denkleminden hareketle Eşitlik 9'da ifade edilen hata düzeltme modeli tahmin edilmelidir. Tablo $6^{\prime}$ da değişkenlere ait kısa dönem katsayıları ve olasılık değerleri yer almaktadır.

Tablo 6: ARDL Hata Düzeltme Modeli Sonuçları ve Kısa Dönem Katsayıları

\begin{tabular}{lcccccc}
\hline & Tarım & Imalat & Toptan & Finans & Hizmet & Madencilik \\
\hline$\Delta Q_{i(t-1)}$ & $0.98^{* * *}$ & & & $0.27^{* * *}$ & & $0.51^{* * *}$ \\
$\Delta Q_{i(t-2)}$ & & & & $-0.46^{* * *}$ & & $-0.36^{* * *}$ \\
$\Delta G$ & -0.049 & -0.05 & -0.025 & $0.179^{* *}$ & -0.031 & $0.13^{* *}$ \\
$\Delta G_{(t-1)}$ & & $0.138^{* *}$ & $0.125^{* *}$ & & $0.14^{* * *}$ & \\
$\Delta G_{(t-2)}$ & & $0.15^{* * *}$ & & & $0.14^{* * *}$ & \\
$\Delta M$ & 0.047 & $0.135^{* *}$ & $0.165^{* *}$ & $0.302^{* * *}$ & $0.089^{*}$ & $0.25^{* * *}$ \\
$\Delta M_{(t-1)}$ & $0.32^{* * *}$ & & $0.153^{* *}$ & & & $-0.44^{* * *}$ \\
$\Delta U N$ & $0.118^{*}$ & $-0.32^{* * *}$ & $-0.27^{* * *}$ & $-0.21^{* * *}$ & -0.037 & -0.021 \\
$\Delta E X$ & $0.21^{* *}$ & $0.20^{* * *}$ & $0.23^{* * *}$ & $0.33^{* * *}$ & $0.09^{* *}$ & -0.034 \\
$\Delta O I L P$ & 0.064 & $0.07^{* * *}$ & $0.12^{* * *}$ & $-0.14^{* * *}$ & -0.022 & 0.049 \\
$\Delta O I L P_{(t-1)}$ & & & & $0.18^{* * *}$ & $0.10^{* * *}$ & \\
$C$ & $0.02^{* *}$ & 0.00 & 0.01 & -0.00 & $0.008^{* *}$ & -0.00 \\
$E C M_{(t-1)}$ & $-2.0^{* * *}$ & $-0.94^{* * *}$ & $-0.58^{* * *}$ & $-0.64^{* * *}$ & $-0.99^{* * *}$ & $-1.1^{* * *}$ \\
\hline
\end{tabular}

Not: $* * *, * *$ ve $*$ sırasıyla \%1, \% 5 ve \% 10 önem düzeyinde anlamlılığı göstermektedir.

Hata düzeltme katsayısını ifade eden ECM terimi, olması gerektiği üzere negatif işarete sahip ve istatistiksel açıdan anlamlıdır. Döviz kuru ve sektörel çıktı arası kısa vadeli ilişkiler incelendiğinde ise madencilik sektörü dışındaki tüm sektörlerin üretim hacmi üzerinde nominal kurların daraltıcı etkisinin bulunduğu görülmektedir. Elde edilen katsayılara göre kısa dönemde döviz kuru madencilik sektörü dışındaki diğer sektörlerin üretim hacmi üzerinde istatistiksel olarak anlamlı pozitif etkiye sahiptir. 


\section{Sonuç}

Nominal döviz kuru ve sektörel çıktı hacmi arasında uzun dönemli ilişkinin varlığını sınamak amacıyla yapılan bu çalışmada, Bahmani-Oskooee ve Mirzaie (2000) çalışmasındaki metodoloji izlenerek 1998.Q1-2015Q3 dönemini kapsayan üçer aylık verilerle ekonometrik analizler yapılmıştır. Nominal döviz kuru ve sektörel çıktı hacmi arasındaki ilişkinin varlığı araştırılırken Türkiye ekonomisi, tarım-ormancılık-balıkçılık, imalat, toptancılık, inşaat, finans ve sigorta faaliyetleri, hizmet ve madencilik sektörleri olmak üzere toplamda yedi alt sektör bazında değerlendirilmiştir. Bu bağlamda öncelikle ADF ve PP birim kök testleri kullanılarak serilerin durağanlık sınaması yapılmış ve bunu takiben seriler arasında uzun dönemli ilişkinin olup olmadığının tayini amacıyla sınır testi aşamasına geçilmiştir. Yapılan sınır testi sonucunda inşaat sektörü dışında kalan diğer altı sektörde uzun dönemli ilişki olduğuna dair bulgulara erişilmiştir. ARDL yöntemi ile elde edilen uzun dönem katsayılarına göre imalat sanayi gibi ithal girdi kullanımının yoğun olduğu sektörlerde nominal kur artışı, yarattığı maliyet etkisi nedeniyle toplam çıktı hacmini olumsuz yönde etkilemektedir. Ancak çıktı düzeyinin hava koşullarına bağlı olduğu tarım sektöründe bu etkileşim negatif yönlü olsa dahi istatistiksel olarak anlamlı değildir. 


\section{Kaynaklar}

Agenor, P.(1991), “Output, Devaluation and the Real Exchange Rate in Developing Countries", Review of World Economics, 127(1), 18-41.

Aguirre, A. ve Calderon, C. (2005), "Real Exchange Rate Misalignments and Economic Performance", Central Bank of Chile Working Papers, Paper No: 315.

Ay, A., Şaylan, Ş. ve Koçak, ì. (2008), "Reel Döviz Kuru ve Çıktı Arasındaki Nedensellik illişkisi: Türkiye Örneği (19902006)", S.Ü. iiBF Sosyal ve Ekonomik Araştırmalar Dergisi, 8(15), 361-374.

Bahmani-Oskooee, M. ve Mirzaie, A. (2000), "The Long-Run Effects of Depreciation of the Dollar on Sectoral Output", International Economic Journal, 14(3), 51-61.

Branson, W.H. ve Love, J.P. (1986), "Dolar Appreciation and Manufacturing Employment and Output”, NBER Working Paper Series, Working Paper No. 1972.

Çatık, A.N.(2007), “Daraltıcı Devalüasyon Hipotezi: Türkiye Üzerine Bir Uygulama”, Gazi Üniversitesi Ekonomik Yaklaşım Dergisi, 18(62), 61-79.

Dickey, D.A. ve Wayne, F. (1981), "Likelihood Ratio Statistics for Autoregressive Time Series with a Unit Root", Econometrica, 49(4), 1057-1072.

Edwards, S.(1986), "Are Devaluations Contractionary”, Review of Economics and Statistics, 68(3), 501-508.

Engle, R.F. ve Granger, C.(1987), "Co-integration and Error Correction: Representation, Estimation and Testing", Econometrica, 55(2), 251-276.

Granger, C.W. ve Newbold, P. (1974), "Spurious Regressions in Econometrics”, Journal of Econometrics, 2(1974), 111120.

Gujarati, D. (2004), Basic Econometrics, The Mcgraw Hill Companies.

Gylfason, T. ve Schmid, M.(1983), “Does Devaluation Cause Stagflation?”, The Canadian Journal of Economics, 16(4), 641-654.

Ibrahim, M.H. (2007), "Sectoral Effects of Ringgit Depreciation Shocks", Journal of Economic Development, 32(2), 135156.

İşcan, T. (1997), “Devaluations and Aggregate Output Fluctuations: A Random Coefficient Regression Model for Mexico", Applied Economics, 29(12), 1575-1584.

Johansen, S. ve Juselius, K. (1990), “Maximum Likelihood Estimation and Inference on Cointegration”, Oxford Bulltein of Economics and Statistics, 52(2), 169-210.

Kandil, M. ve Mirzaie, A. (2002), "Exchange Rate Fluctuations and Disaggregated Economic Activity in the US: Theory and Evidence", Journal of International Money and Finance, 21, 1-31.

Köse,N., Ay, A. ve Topallı,N.(2008), “Döviz Kuru Oynaklığının İhracata Etkisi: Türkiye Örneği (1995-2008)”, Gazi Üniversitesi IiBF Dergisi, 10(2), 26-45.

Krugman, P. ve Taylor, L. (1978), “Contractionary Effects of Devaluation”, Journal of International Economics, 8(1978), 445-456.

Krugman, P.R., Obstfeld, M. ve Melitz, M.(2012), International Economics: Theory and Policy, Addison-Wesley Publishing Company, 9th Edition.

Küçükkiremitçi, O. (2011), "Türkiye Sanayi Strateji Belgesi Temelinde İmalat Sanayinin Yapısal Analizi", Memleket, Siyaset, Yönetim, 15(2011), 53-94.

Masunda, S. (2011), "Real Exchange Rate Misalignment and Sectoral Output in Zimbabwe”, International Journal Economic Research, 2(4), 59-74.

Pesaran, H., Yongcheol, S. ve Shin, R. (2001), "Bounds Testing Approaches to the Analysis of Level Relationship", Journal of Applied Econometrics, 16(3), 289-326.

Perron, P. ve Phillips, P. (1988), “Testing for a Unit Root in Time Series Regression”, Biometrica, 75(2), 335-346.

Sarı, A. (2009), “Çıktıya (GSMH) Para Arzındaki Büyümenin, Faiz Oranı Oynaklığı ve Döviz Kuru Oynaklığının Etkileri: Türkiye Örneği", Afyon Kocatepe iiBF Dergisi, 11(2), 19-36.

Toulaboe, D. (2006), "Real Exchange Rate Misalignment and Economic Growth in Developing Countries", Southwestern Economic Review, 33(1), 57-72.

TÜiK(2002), Türkiye Ekonomisinin Arz Kullanım ve Girdi-Çıktı Tabloları. 


\section{Eskişehir Osmangazi Üniversitesi IïBF Dergisi}

Uğurlu, E. (2009), “Real Exchange Rate and Economic Growth: Turkey”, Manas Üniversitesi Sosyal Bilimler Dergisi, 22, 191-212.

Zivot, E. ve Jihaui, W. (2006), Modelling Time Series with S-Plus, Springer: Second Edition. 